(C) 1980. The Genetical Society of Great Britain

\title{
NATURAL SELECTION IN EXPERIMENTAL POPULATIONS OF THE LANDSNAIL CEPAEA NEMORALIS (L.)
}

\author{
C. R. BANTOCK* and M. RATSEY $†$ \\ *Department of Biology and Geology, The Polytechnic of North London, Holloway Road, London N7; \\ +Cobbhay Farm, Milverton, Taunton, West Somerset
}

Received 6.vii.79

\begin{abstract}
Summary
A field experiment with Cepaea nemoralis is described. Twenty cages, designed to exclude vertebrate predators, divided equally between five sites at different altitudes in a single valley, were populated by adult snails taken from a $180 \mathrm{~m}$ population sampled in adjacent $10 \mathrm{~m}$ "donors". The population showed a steep cline in morph frequencies. Each morph from each donor was apportioned equally between the cages. Between May and October 1974 more than half the snails died. There were position-dependent differences in mortality, and survival was greater where the morph frequencies in the original population were clinal. Repeated differences in survival between the morphs occurred at four sites, and these were opposite in direction between two of them. Brown-shelled snails survived best at an apparently cool site and worst at an exposed one. Overall, yellow five-banded snails survived better than the other morphs.

It is suggested that overcrowding is a primary source of stress for all the morphs, and that temperature is important in determining the selective outcome between them. Alternative interpretations are given. It is concluded that the population cage provides a useful tool for the study of natural selection in Cepaea.
\end{abstract}

\section{INTRODUCTION}

ONE of the primary concerns of the ecological geneticist is the practical study of directional selection. The stopping point for many such studies is the demonstration that spatial variations in morph or gene frequency are statistically related to particular environmental variables; the result is used to generate hypotheses causally relating the variables by simple inference. Subsequent steps in the study could entail the demonstration that selection occurs on the traits in question, the measurement of its intensity, and the identification of its cause. These steps have rarely been taken.

The colour and banding shell polymorphism of the landsnails Cepaea nemoralis (L.) and $C$. hortensis (Müller) is a typical case. In a recent review of this polymorphism, Jones et al. (1977) cite 201 references, 58 of which itemise work describing geographical variation in morph frequency. Of this number 38 propose the selective importance of climatic factors, temperature and humidity in particular being implicated. However, there are only two recent studies (Jones and Parkin, 1977; Garcia, 1978) which specifically attempt to determine experimentally whether climatic factors could operate selectively, the former involving the transplantation of populations of $C$. vindobonensis (Pfeif.) between topographically different sites, and the latter the study of survival rates of different morphs (of $C$. nemoralis) under controlled conditions in incubators. The first experiment failed to demonstrate selection, and a criticism of the second is that the results may not assist in interpreting natural populations. 
The relative paucity of experimental data relating to selection by climate may in part be due to the difficulty in defining an appropriate experiment (A. J. Cain, personal communication). A further difficulty lies in experimental design. Clarke et al. (1978) provide a critique of the evidence for selection in pulmonate snails and point out that much of the experimental data purporting to show climatic selection is uninterpretable since authors have failed to distinguish inter-morph from inter-population differences in fitness. If two populations differ in morph frequency, the effect of selection can be produced if the populations are grouped together and there are experimental differences in survival between them. Unfortunately there are few guidelines as to what is meant by a population in Cepaea. Lamotte (1951), on the basis of migration distances of marked individuals, suggests that the panmictic unit is about $50 \mathrm{~m}$ long, and most field workers have used this as a guide in determining the extent of their sampling areas. However, there is no reason to suppose that all populations of this extent are always genetically homogenous; considerable changes in morph frequencies over much shorter distances are known (e.g., Wolda, 1969). The interpretation of these morph-ratio clines is problematic, but if they reflect underlying differences in genetic background then the possibility of inter-population differences in survival occurring under experimental conditions is a real one. Clearly, what is required is the demonstration that the same selective differences between morphs occur in a statistically sufficient number of independent replicates, in spite of possible differences in morph frequency and mortality between the replicates. The individuals comprising each replicate would have to be collected from areas small enough for any change in morph frequency over short distances to be detected.

Glimate can operate directionally on the shell polymorphism only if there are potential differences in fitness between the morphs. There are so many morphs in $C$. nemoralis and $C$. hortensis, that by chance alone the survival of one of them is likely to appear to be determined by climate. However, if an array of differences in fitness between the morphs can be demonstrated, with outcomes which differ under different physical conditions, then the generality of the importance of climate is more likely. Bantock (1974) described an experiment involving the use of field population cages in which the survival rates of different morphs of adult $C$. nemoralis were different, but the design did not allow inter-morph and inter-population differences to be distinguished. The purpose of the present paper is to describe the results of a more ambitious experiment with this species, using cages at different sites, and a more rigorous design allowing the comparison of survival of different morphs taken from a series of small areas. This technique has recently been used by Knights (1979) to show the selective effects of insolation on $C$. hortensis of different size. The main purpose of the present experiment was to determine whether inter-morph differences in survival could be detected at a variety of different sites.

\section{Material AND methods}

(i) The study area

The experiment was carried out in the grounds of The Leonard Wills Field Centre, Nettlecombe, Somerset. The main reason for this choice of study area is that field experiments can be carried out without unauthorised 


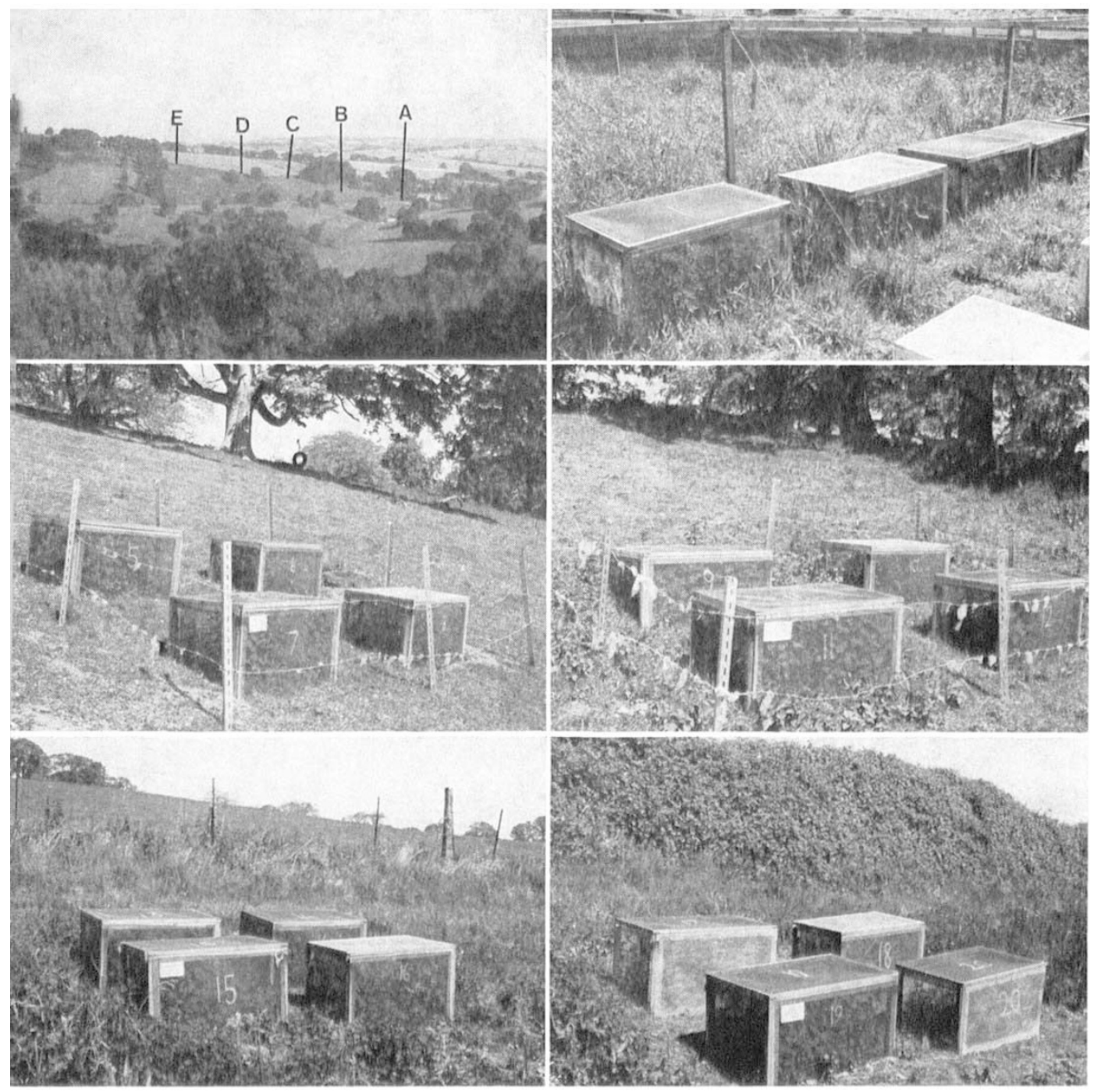

Plate I.-The experimental sites. Top left: Nettlecombe Valley from the south-east. The five sites are indicated (A-E). Top right: Site A (Cages 1-4). Middle left: Site B (Cages 5-8). Middle right: Site C (Cages 9-12). Bottom left: Site D (Cages 13-16). Bottom right: Site E (Cages 17-20). 
human disturbance. Other reasons are that Nettlecombe valley is topographically extreme, with a local climate known to be continental in type (Ratsey, 1973), and that it is part of a much larger area in which morph frequency variation in Cepaea is known (Bantock and Price, 1975).

\section{(ii) The cages}

Twenty were used. Each consisted of a wooden frame $(1 \mathrm{~m} \times 0.61 \mathrm{~m} \times$ $0.76 \mathrm{~m}$ ) with a hinged lid. The sides and top were covered with $7 \mathrm{~mm}$ plastic mesh and the bottom with $13 \mathrm{~mm}$ chicken wire. The cages were divided equally between five sites (A-E), with site A (cages 1-4) on the valley floor and sites B-E at different altitudes on the east-facing slope of the valley. Site B (cages 5-8) was $18 \mathrm{~m}$ above the valley bottom on a steep slope topped by a clump of large trees. This site was in shade from about 1500 hours daily. Site $G$ (cages 9-12) was a further $16 \mathrm{~m}$ above $B$ and on a small exposed hummock. These three sites (A-C) were in fields of grass kept short either by grazing or mowing. Sites $\mathrm{D}$ and E (cages 13-16 and 17-20 respectively) were 22 and $38 \mathrm{~m}$ above $\mathrm{C}$, in an extensive patch of bracken and nettles. The five sites and a general view of the valley are shown in Plate 1.

The cages were put out in February 1974. Each was buried $10 \mathrm{~cm}$ in the ground, the soil replaced and planted with nettles. Care was taken to ensure that the amount of vegetation planted in each was the same. Grass seed was sown in the cages in April. By the time the snails were put out the vegetation was well established in all 20 cages; thistles were removed from two of them.

\section{(iii) The snails}

The chief requirement was a population of $C$. nemoralis which was both polymorphic and sufficiently dense to provide enough individuals of the different morphs to allow a realistic comparison between their performances in the cages to be made. Such a population was found (during 1973) $10 \mathrm{~km}$ west of Nettlecombe at Dunster, West Somerset SS94 6026-6827. It occupied a continuous, apparently uniform bank-hedge about $1.5 \mathrm{~m}$ high, running east-west. $180 \mathrm{~m}$ of this population was sampled between 25-28th May 1974, in $10 \mathrm{~m}$ sections which will subsequently be referred to as donors. Only adults were taken; they were stored temporarily in canvas bags at room temperature. 4251 snails were collected, giving a mean of 236.2 (s.d. 69.9) per donor and indicating a density of about 16 adults per square metre. There was no sign of systematic changes in density between the donors.

Seven morphs were present: brown unbanded (B0), pink and yellow mid-, five-, and un-banded (P3, P5, P0, Y3, Y5, Y0). These were not equally common, and there were large differences in frequency between the donors (table 1). Between donors 1 and $9 \mathrm{~B} 0$ was present at a mean frequency of 54.5 (s.d. 3.4), but between donors 10 and 12 it dropped 22 per cent from 53 to 31 per cent, and a further 6 per cent by donor 15, remaining at 28 per cent up to donor 18. The decrease in the frequency of this morph over the $60 \mathrm{~m}$ between donors 10 and 15 was accompanied by a steep increase in the frequency of pink, and a more gradual increase in yellow. Mid-banded, expressed as a percentage of banded snails, increased gradually from 45 per 
TABLe 1

\begin{tabular}{crrrrrrrr}
\multicolumn{7}{c}{ Adult morph frequencies in the $180 m$ population used in the experiment } \\
Don & B0 & P0 & Y0 & P3 & P5 & Y3 & Y5 & Total \\
1 & 68 & 6 & 0 & 17 & 5 & 24 & 3 & 123 \\
2 & 116 & 4 & 0 & 30 & 4 & 54 & 6 & 214 \\
3 & 111 & 1 & 0 & 34 & 2 & 50 & 10 & 208 \\
4 & 70 & 1 & 0 & 22 & 4 & 40 & 5 & 142 \\
5 & 79 & 2 & 0 & 23 & 6 & 41 & 3 & 154 \\
6 & 99 & 1 & 0 & 26 & 4 & 35 & 2 & 167 \\
7 & 145 & 0 & 0 & 46 & 12 & 64 & 10 & 277 \\
8 & 165 & 0 & 0 & 40 & 7 & 59 & 8 & 279 \\
9 & 96 & 3 & 0 & 28 & 7 & 28 & 9 & 171 \\
10 & 121 & 2 & 0 & 42 & 8 & 41 & 14 & 228 \\
11 & 96 & 2 & 1 & 62 & 13 & 56 & 9 & 239 \\
12 & 92 & 5 & 1 & 69 & 22 & 91 & 18 & 298 \\
13 & 80 & 0 & 0 & 69 & 9 & 66 & 11 & 235 \\
14 & 82 & 5 & 3 & 76 & 24 & 134 & 25 & 349 \\
15 & 75 & 2 & 3 & 71 & 9 & 128 & 21 & 309 \\
16 & 90 & 10 & 5 & 58 & 19 & 112 & 23 & 317 \\
17 & 59 & 9 & 2 & 32 & 9 & 78 & 11 & 200 \\
18 & 97 & 19 & 9 & 62 & 16 & 112 & 26 & 341 \\
Total & 1741 & 72 & 24 & 807 & 180 & 1213 & 214 & 4251
\end{tabular}

$\mathrm{B}=$ brown $; \mathrm{P}=$ pink $\mathrm{Y}=$ yellow $; 0=$ unbanded $; 3=$ mid-banded $; 5=$ five-banded; Don $=10 \mathrm{~m}$ donor.

cent in donor 1 to 50 per cent in donor 13, but then dropped abruptly to 34 per cent by donor 15 , remaining at that level until donor 18 .

These changes in morph frequency are shown in fig. 1 (a) and indicate that the original $180 \mathrm{~m}$ population is characterised by two different states of morph frequency variation with a steep cline between them. The locus controlling the pattern of banding is unlinked to that controlling colour (Gain, Sheppard, and King, 1968) so that in reality there are two independent and coincident clines.

Table 1 reveals that $\mathrm{P} 0$ and $\mathrm{Y} 0$ were present at low frequencies; they were judged to be too infrequent to provide sufficient numbers for the cages and were not used. Twenty-three snails were newly-adult with shells unsuitable for marking; the remaining 4132 were marked by donor-specific drill holes. The snails were allocated to 20 experimental groups so that each morph from each donor was represented equally in each. There were small differences between the totals in the groups, since the numbers representing a particular morph were rarely exactly divisible by 20 . Y3 and Y5 were rare between donors 1 and 9 so that some of these donors were either not represented in the groups by these morphs, or only by single individuals.

The snails were put out, one group per cage, at dusk on 31 May and scored for mortality on 2nd October 1974.

\section{(iv) Analysis}

Two non-parametric methods have been employed to analyse the relationships between the variables: sites $(\mathrm{S})$, cages $(\mathrm{C})$, donors (D), morphs (= forms) (F), and mortality $(\mathrm{M})$.

1. The log-likelihood ratio (G) test (Sokal and Rohlf, 1969). This has the advantage over $\chi^{2}$ in allowing the simultaneous analysis of multiway frequency data. An a priori test of partitions gives in a single operation an 

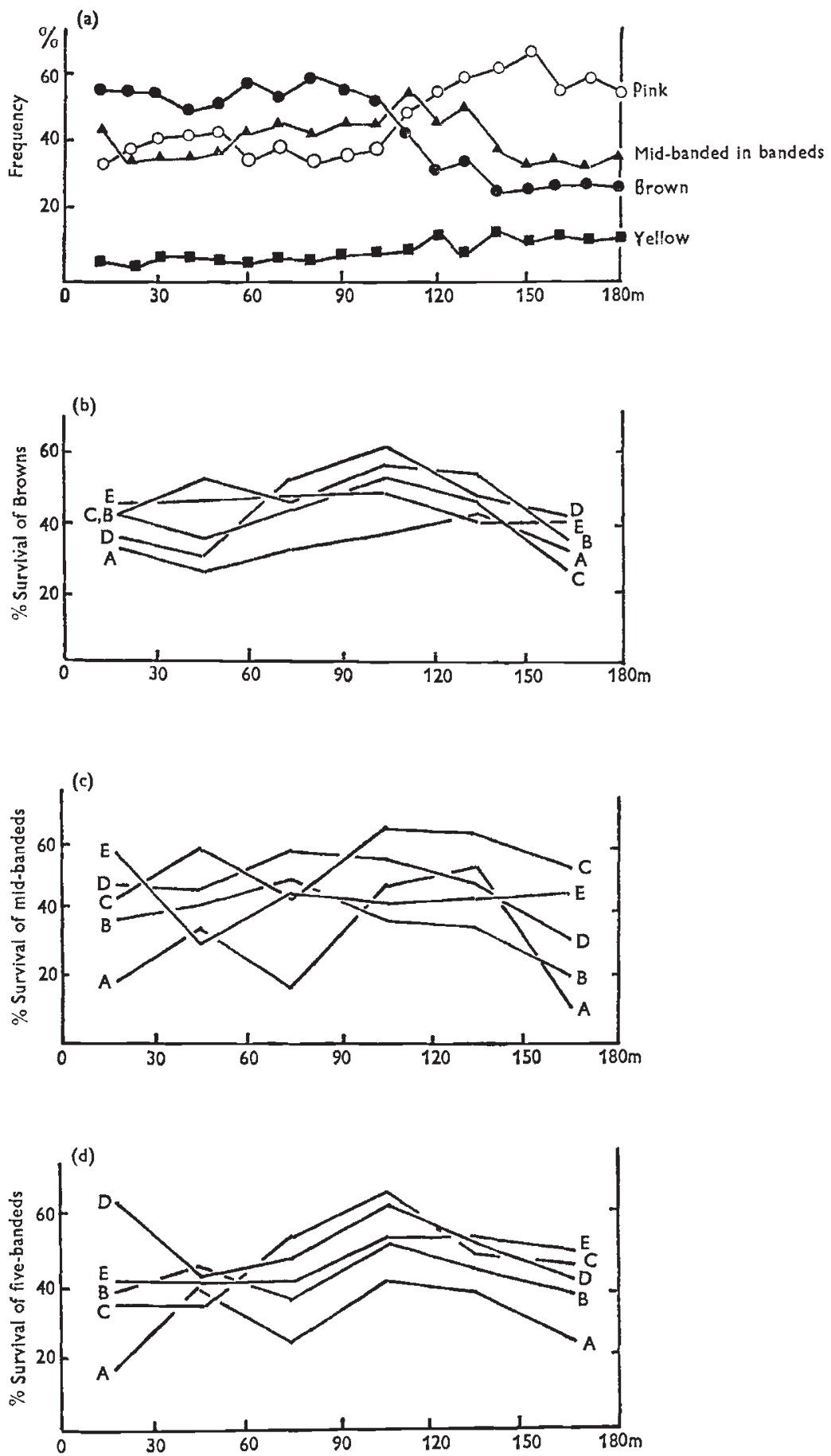

Frg. 1.-(a) Morph frequency variation in the $18 \times 10 \mathrm{~m}$ donor populations used in the experiment. (b)-(d) Survival at each site (A-E) of browns (b), mid-bandeds (c), and five-bandeds (d). The data for adjacent $10 \mathrm{~m}$ donors have been combined to make $6 \times 30$ groups. 
overall test of independence between all the variables, separate tests of independence between any two, as well as tests of interaction. The test statistic $(G)$ is additive, so that the sum of interaction and independence $G$ s equals the overall independence $G$ : a useful check on accuracy. In cases of significant results in the tests of independence an a posteriori Simultaneous Test Procedure (STP) allows the source of the significance to be determined. Hayward and Harvey (1974) give a worked example of a three-way G test.

2. Wilcoxon's signed-rank paired-samples test has been used to compare the proportions surviving of the different morphs. Two proportions relating to a single donor constitute the members of a pair, and the different donors comprise a series of pairs.

There is an important restriction on the analysis. Both $\mathrm{G}$ and $\mathrm{T}$ tests involve comparisons between proportions based on frequencies. For such comparisons to be valid it must be shown that at least one observation would be expected to occur in every cell of a contingency table assuming that the total number of observations is distributed between the cells in proportion to the margin totals. This condition has been met by combining the data relating to adjacent donors where necessary. In order to carry out biologically realistic data-grouping for the $T$ tests, combinations of data from different donors have been restricted to involve a maximum of three adjacent donors, as this does not exceed the panmictic unit; in most cases the combinations involve smaller groups. This further restriction has frequently necessitated combining the data for the different cages at a site, and in a few cases dropping observations from the analysis. Wherever possible, where morphs have been compared with the data for the different cages combined, the result has been reanalysed, keeping the data for the cages separate and analysing the four sets serially.

Differences in survival between snails from the different donors in the cages at each site have been analysed by separate three-way (CDM) G tests for each of the three most abundant morphs (B0, P3, P5). Datagrouping has been restricted to three adjacent donors except in two cases where mortality was high; one involves six adjacent donors (P3 at site A), the other $4 \times 40 \mathrm{~m}$ groups (P3 at site $\mathrm{E}$ ). Since the two yellow morphs represent each donor in each cage by single figures in many cases, the data for the different donors have been combined for two-way analysis of differences in mortality between the cages, and those for the different cages have been combined for two-way analysis of differences in mortality between the donors.

A four-way analysis (cage, donor, morph, mortality), which could encompass both the above $\mathrm{G}$ and $\mathrm{T}$ tests together, is theoretically possible, but is not practicable since it would entail loss of information due to the extensive data-grouping that would have to be carried out to fit the structure of the test. The full details of the data-grouping, which differs slightly between sites due to variations in survival, and of the few observations which have been dropped from the analysis, are given in the tables. All the probabilities indicated in the tables are two-tailed.

\section{Results}

During the experimental period no attempt was made to control vegetational change in the cages, so that by October there were sometimes obvious differences between them. 
Of the 4132 snails put out, 18 could not be found when the cages were searched. The plastic mesh of cage 12 (site $\mathrm{C}$ ) had been slightly damaged in two places (probably by bank voles) and 16 snails were missing ( $8 \mathrm{~B}$, $1 \mathrm{P} 3,5 \mathrm{P} 5$, and $2 \mathrm{Y3}$ ). Two further snails (1 B0, $1 \mathrm{P} 5$ ) could not be found in cage 19 (site $\mathrm{E}$ ). The missing individuals have been assumed never to have been put out and accordingly not included in the analysis.

During the course of the experiment 56.6 per cent of the snails died. The raw data are given in table 2 . The patterns of mortality will be considered at three levels.

\section{(i) Comparison of survival between donors and cages, within morphs, within sites}

Table 3 gives the results of three-way and two-way $G$ tests on the mortality of each morph at each site.

Site A: 68 per cent of the snails died. There is no difference in mortality between the cages, but for B0 and P3 there are significant differences in mortality between the donors. The relevant STP's show that B0 individuals from donor $3+4$ had a lower survival than those from $13+14$ and that P3 from donor 16-18 had a lower survival than those from donor 10-12.

Site B : 56 per cent of the snails died. There are no overall differences in mortality either between the cages or the donors, but for B0 and P5 the mortality of snails from different donors is significantly different between the different cages.

Site $C: 52$ per cent of the snails died. There are no differences in survival between the cages, but for B0 and P3 there are differences in mortality between the donors for the different cages. Notwithstanding this heterogeneity there are overall highly significant differences in mortality between the donors; B0's from donor 5 survived less well than those from 10 and 12, and P3's from $7+8$ had a lower survival than those from $9+10,11+12$, and $13+14$.

Site D: 53 per cent of the snails died. There are no differences in mortality between the cages, but for P3's there are highly significant differences between the donors; snails from donor 4-6 had a lower survival than those from $9+10,11+12$, and $13+14$.

Site E: 54 per cent of the snails died. For B0, P3, and P5 there are differences in mortality between the cages; in each case mortality was higher in cage 20. The only differences in survival between donors is for Y3 where snails from $8+9$ and 18 had a lower survival than those from $6+7$. For P5 there is significant variation in mortality between the donors between the cages.

It is useful to consider to what extent these results might be attributable to random effects. Of $25 \mathrm{CM}$ tests of independence, three are significant (one is highly so) and the STP's show that in each case it is in cage 20 (site E) that there was the worst survival of snails. Three significant results with the same cause are more than would be expected by chance alone in a run of 25 ; it seems likely that the differences in mortality between the cages at this site are real.

Of 15 CDM tests of interaction five are significant, one of them highly so. This implies that survival of individuals from different donors varies between the cages at some of the sites. In spite of this heterogeneity there is evidence of overall differences in survival between the donors; six of the 25 DM tests 


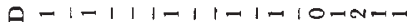
0 1 $0101110110101-0000$

a - $111111-100001000$

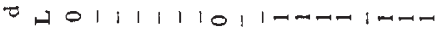

D HNNTOM-NTOMNTMmont

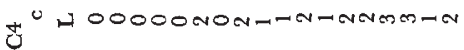

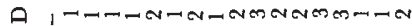

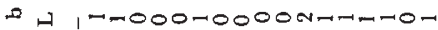

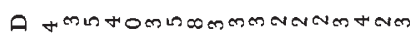

IH OMOA HNNOMMNMNN-TON

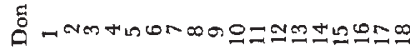

D 1 $11-1101-\pi 1-0--01-$ - H, 1 10,1-10010-00-1-

D $1111-1011--01--\pi 11$ ช日111101-1100-100011

A -Nm-nommonamesentht $8^{\circ}$ -

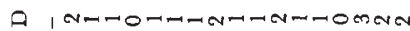

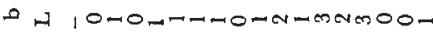

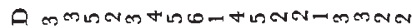

तम

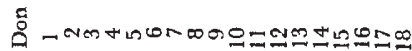

A $101111-110-0-00-1=$ OH 1-1111011-0-0-10 A $11-11-11-1-0100-1-$ D, $11011011010-1-2010$

A OMn-Amm-ONeverionentis ₹

A TN-NOON-TNATMENANA

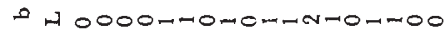

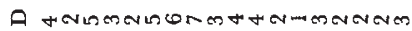
"H OH-OMO-NWN-NM-NNT-

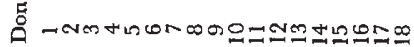

Q 1ーー1 1 1 1-0 1 1-1-ーー10 10011110-110100-1-

A $1-1111-1100$ NON $1-10$ ग 101111011 $10-0-0101-$

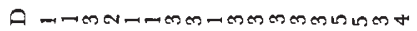

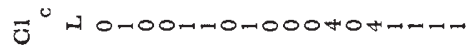

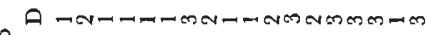
1 $000-00000$ m-n-1-1000 A trismencomentranceneren

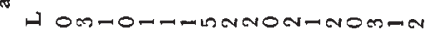

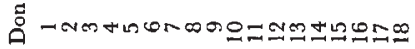

A 1101110111 10-100-

m $11-1,1-111001-0-\pi 0$

a 11101110101-001-ー-

त $1110111-1-10-1000$

A O-OMn-ONON-AHATOM

\& H TMN-OOM-TONmOMmNma

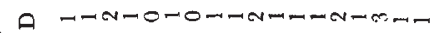

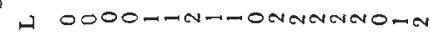

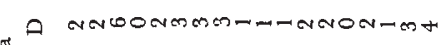

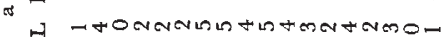

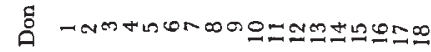

o $11-1,1$

H 110011

$\theta 0111101$

a $1111-1$

०คーーーーー บ म คดーーーーーー

$100-000$

a mennmon-

a OH-OOH

ह -

A $111-11011-1000-0$ H $111011-1101-7 m 0-00$

A $1111-1-110-01 m-010$

H $11110101100-100-10$

A O-OO-Nen-NONm-mttrm

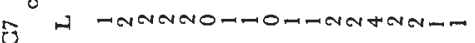

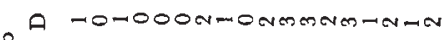

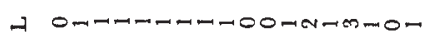

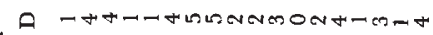

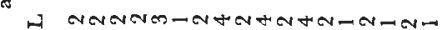

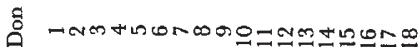

- $1+11-1$ A 11101

- 0111110 月111110 a $-\mathrm{ON}-\mathrm{N}-\mathrm{O}$ च म MnO-NA - - 0 -O-O n OーMーOー

a minatara A O-NTOM

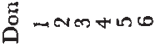

A $1-10111-101---0-10$ H 101-11101-1000-01-

A $111-11-1-1-0101-1-$ o $11101101010-101010$

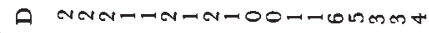

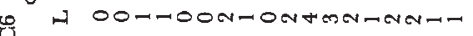

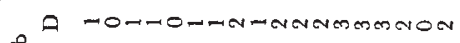

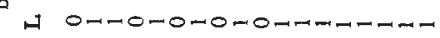

A NHevomminmeramat-m

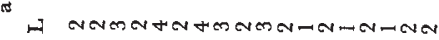

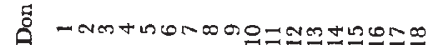

$\theta-1-1+1$ HO 10111 D 111110 - 111110 A TNenerare OH $100-000$ - A - $0000-$ nOMNMーー D O-mato a minteron

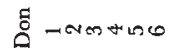

o $111111110010100-10$ A $11111111-01$ 1-0010 A $1-111-10111$-ーーーーー 1 N $1011101-1110000001$

A OO-n-mN-mmarmon-t

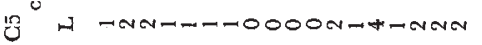

A 1-ーーーーーーH 1-HO-OM-ONN-NoO-0

A meverencisinento-trenten

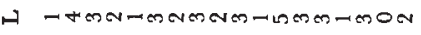

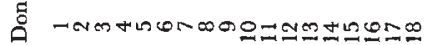

Q 110110 म $11-11-$

D 110110 - $1,-110$

a honero 8 Nerroon

- A m-noNo nooomon

ब vmtenta N 1 -m-ーO คัด - Nmtro 
$1-01-11-0-1=$ $10-1011-2010$ $011011-00011$ $-11-1$ 10-m-1

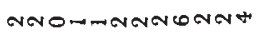
OOMNINNHINNA NHOMONH-NMTO H-mMNNmWNOt AHONNNMTHNMT monmmenm-NONm

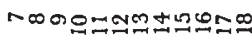

-1 10-0m-00m0 1 1-0-00-mo O I-ININIOIm $-11010101-10$

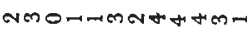
mOMmNNMMNNM

NNM-N-TO-O-M

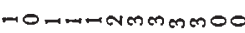
mए NMNNNNMUNm HNMMENNN-OHN

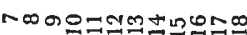

O 1 II I-NONO 1$-1101-000-1-$ $1001-m 101-m 0$ $1--1001-100-$

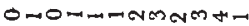
mNNTNAMMHOH NNOO-OH-MO-N OOHMNMNM-NAustrmanesant men INAHANMOヘ

$11001000-000$ 1 1-ー1-ー00ー-0 $1-11$ - $10-010$ $1011001-0-10$

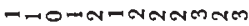

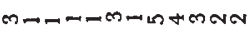
-NOOOHーRNATN -OMNGMNCNAOHtath-N-Nmen mLNNNMNM-NON

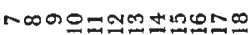

A $111011-1-1-01-0-10$ ค 1 1 1-1 101010-10-0 1N Q $1111-1-11-1=0-1=00$ H $1111010110100010 m$

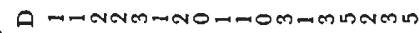
$\frac{6}{U}$ H ON-OOHNM-OM-mNOH-

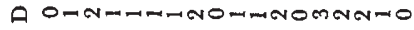

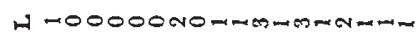
A NHANHTh H momomathNAH manNom

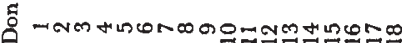

Q 111101117-10000-00 $\rightarrow 1111-111001$-INTO-0 Q 111-111-11001-0010

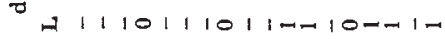

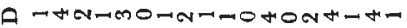

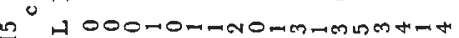
0

A -000-mN-ONN-ONMNNN h OMNmOMOM-OMmm-Omon

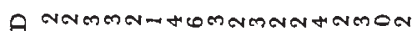
"A -mmontमmNH-NNOO-mm

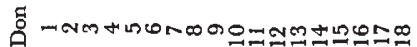

a-1-1111-10100-0000 - 010111101 Q $1111-101-1-01-0-1=$ ชค111101-1010-10-010

A N-MOMONN-IMONMNHNM

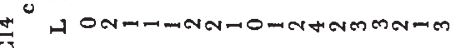
A - -O-MTONON-ONNM-MN

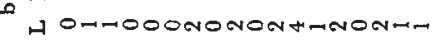
Q NNMNMMN-NMCN-NNNH-N

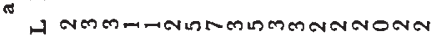

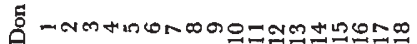

Q $1111-01710-010-70-$ H $11110-101-0-1-00-0$ a $101111010100-1-10$ T A NNNNTNOMOO-MNISITNM

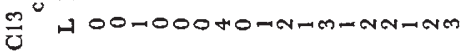
A mon-n-0000-manhwma momocoonervarnamooo-

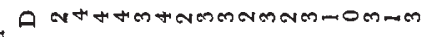

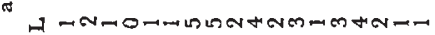

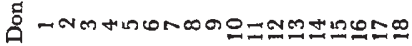

D $100-111110001-7010$

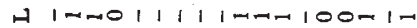

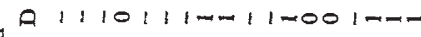
H I 1, 1 1 100110-n1000

A OMNONONNN-Nmotinme

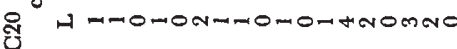

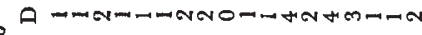
n 00000-00m-00m0-Nor

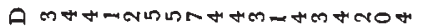

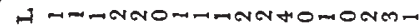

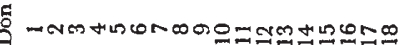

Q 1111110101100 NOM 10 म $11111101-1$ 1 1 O $1111010110-m 1-\pi 010$ ค1 11101011000100-10

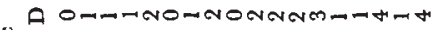

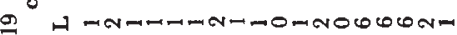

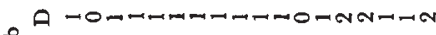

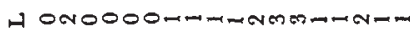

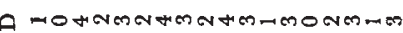
H NHENOMmLNNNH-M-NNN

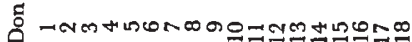
Q $01111010101-000000$

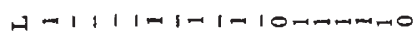
A $11011101-1-1-1001$ $11-111-101001-1=01$

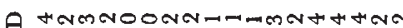
$\infty$ 月 000 -NN-O-NNN-N-mN A OOMNMONONMNOMMNTON I -NOOO-ONO-NMM-NNM-

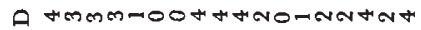

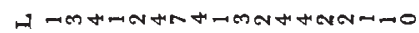

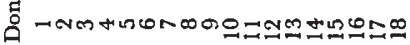
$01001111010101-0,00$

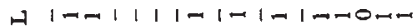
Q 11111001110000110m

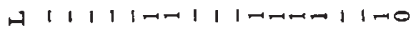

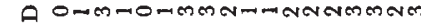

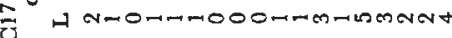

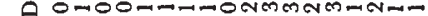

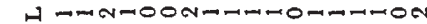
A vermentmen-m then-men A Nmovertmintm-Non-Nmo 号 - Nentur 


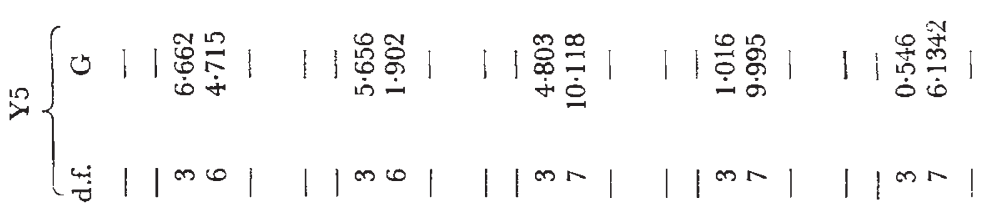

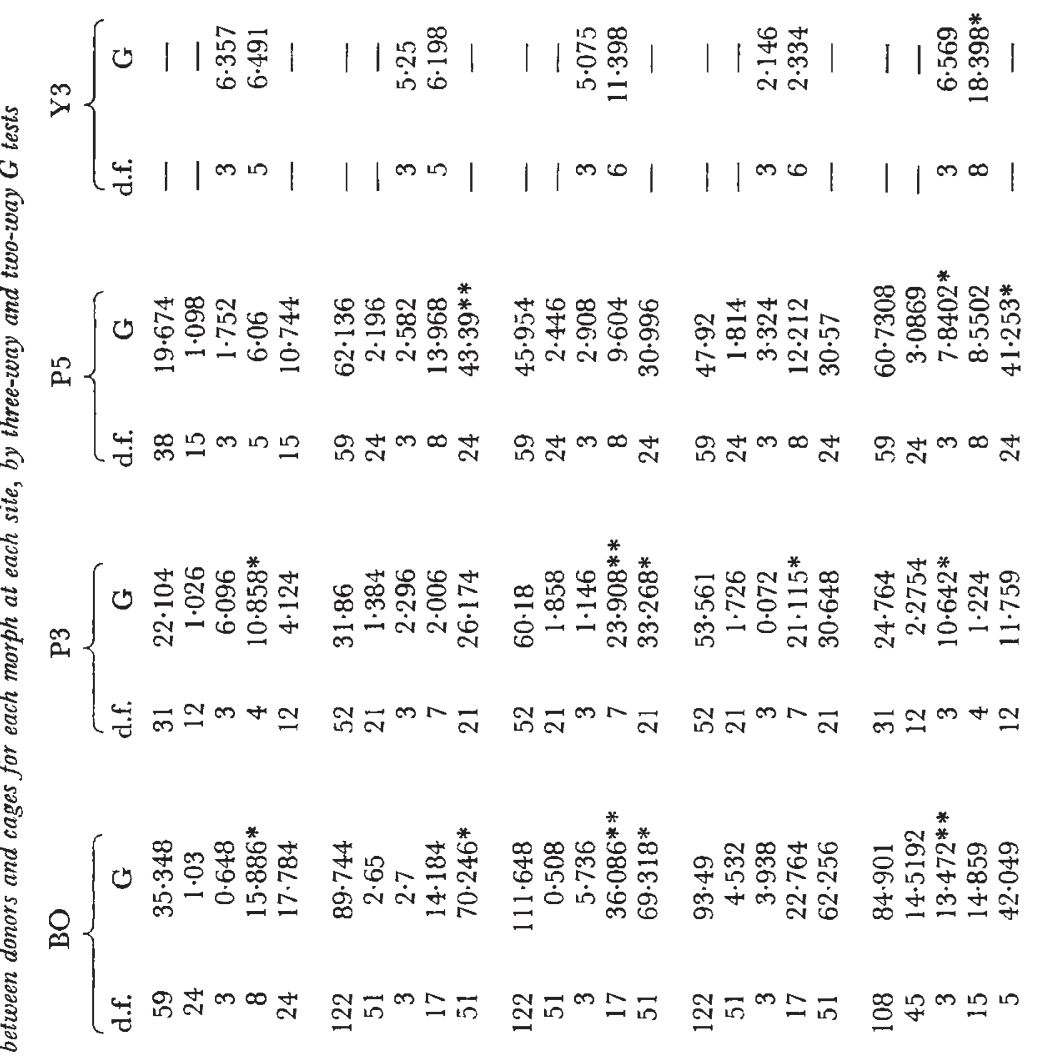

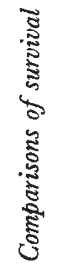

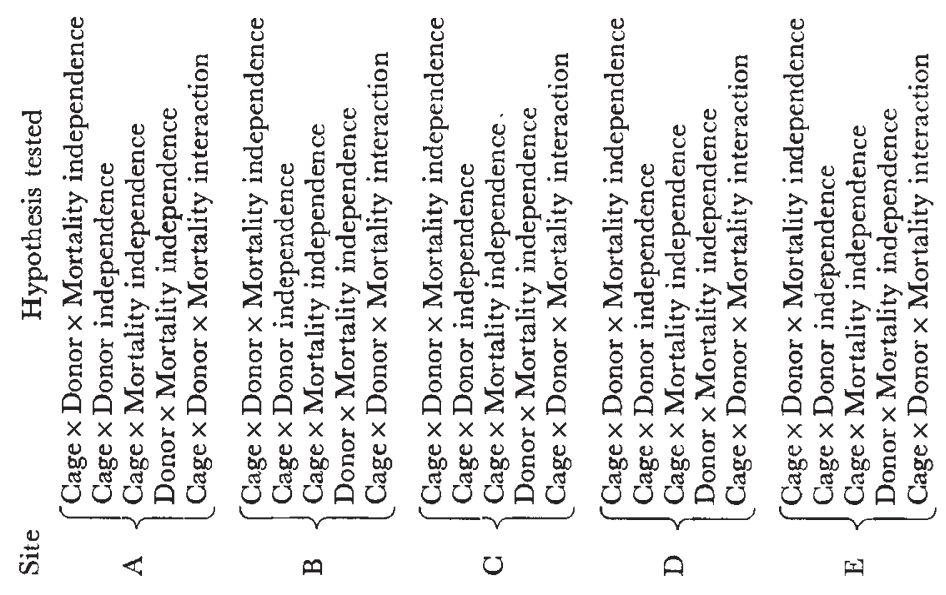


NATURAL SELECTION IN CEPAEA

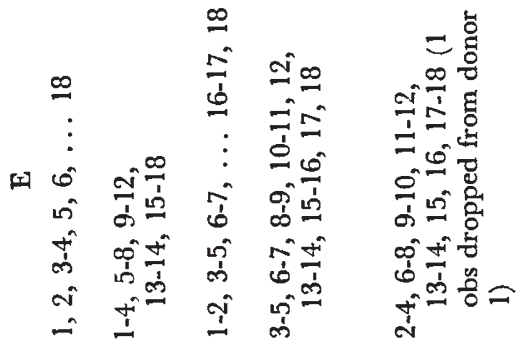

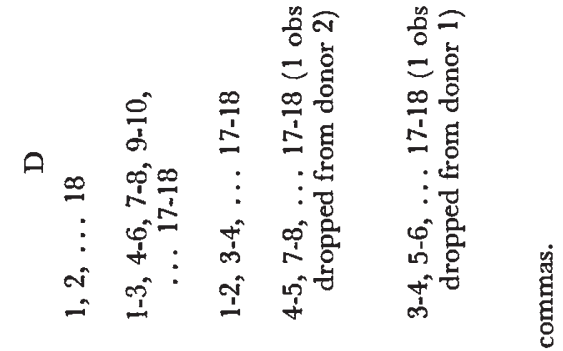

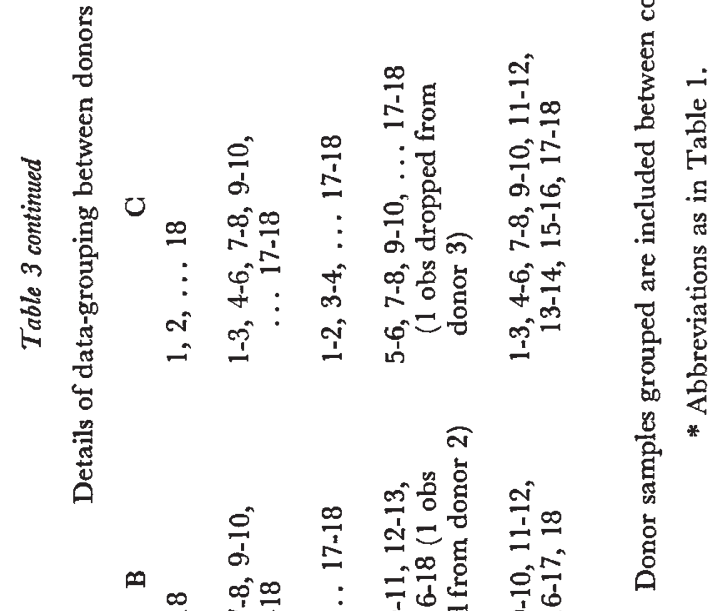

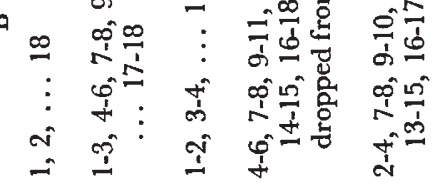

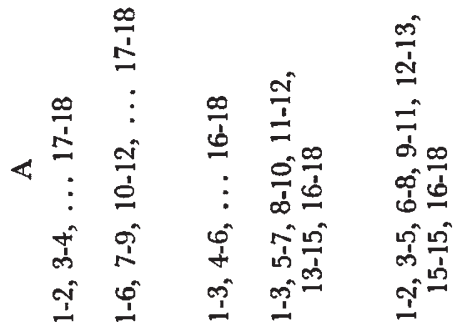

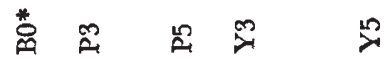


of independence are significant, three of them highly so. This number of significant results is more than would be expected by chance, but what is of particular interest is that there appears to be a trend for snails from donors 9 to 15 to survive better than those from nearer the ends of the whole population. This is particularly marked for P3, but is shown also by B0. In order to examine this effect further the data for the cages at each site have been combined and reorganised into $6 \times 30 \mathrm{~m}$ donor-groups. For each such group at each site percentage survival has been calculated separately for B0, mid-bandeds, and five-bandeds. (This grouping of the morph-data makes the fullest use of the results, since it includes the relatively few figures for the two yellow morphs in the last two categories.) Fig. 1, b-d, shows the survival of each snail type at each site in relation to the six donor-groups. It can be seen that in general survival is high over donors 10-12, and sometimes so over 13-15. Survival is consistently low in 16-18, and less consistently so in 1-3. Reference to fig. la shows that donors 10-15 involve that part of the population in which the morphs show steep changes in frequency, particularly B0's and mid-bandeds. Survival of B0's tends to be highest where the change in frequency is steepest, and this is true also for mid-bandeds. Formal comparisons between the proportions surviving in the different donor-groups have been made by treating the data for the sites and for the three categories of snail serially and carrying out paired-samples tests. There are no significant differences in survival between the donor-groups at the extreme ends of the population $\left(T_{15}=63\right)$ and none between $10-12$ and 13-15 $\left(\mathrm{T}_{15}=40\right)$ over which $60 \mathrm{~m}$ the morph frequencies are clinal. However, the differences in survival between the donor-groups on either side of this region and those adjacent and within it are pronounced; 7-9 v. 10-12 $\left(T_{15}=17.5, P=0.02\right)$ and 13-15 v. 16-18 $\left(T_{15}=7, P=0.003\right)$, even though there is no difference between 7-9 and $16-18\left(\mathrm{~T}_{15}=36\right)$. In addition, the difference between $1-3$ and $10-12$ is significant $\left(T_{15}=17, P=\right.$ $0 \cdot 02)$.

This is clear evidence of a regular difference in survival between particular donor-groups; these differences exist even between adjacent sites within a "panmictic unit".

\section{(ii) Comparison of survival between morphs, within sites}

Table 4 gives the percentage survival of each morph at each site and the results of $T$ test comparisons between them. These reveal complex patterns of intermorph differences in survival.

Site A: The range of differences in survival is 14 . There are no significant differences between the morphs. Y3's survived best and P3's the worst; yellows survived better than pinks but not significantly so.

Site B: (range 26). Y5's survived best and $\mathrm{Y}^{3}$ 's the worst. These survived significantly worse than Y5's, B0's and P5's. Additionally P3's survived worse than Y5's, but there are no differences between P3's, P5's and B0's, between the two five-banded morphs, and between the mid-bandeds. Overall, browns survived significantly better than mid-bandeds, and this is true when the data for the four cages are considered serially as well as in combination.

Site $C$ : (range 12). In contrast to site $\mathrm{B}$, mid-bandeds survived best and B0's the worst. There are no significant differences in survival between 
TABLE 4

Comparisons of survival between morphs--results of Wilcoxon's signed-rank paired-samples tests Site

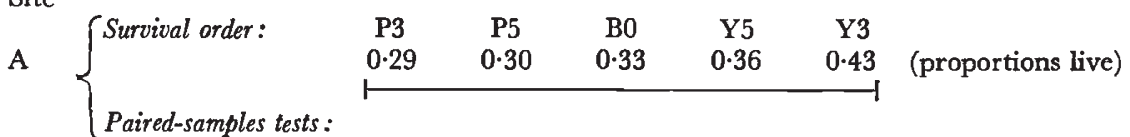

No comparisons significant

B $\left\{\begin{array}{lccccc}\text { Survival order: } & \text { Y3 } & \text { P3 } & \text { P5 } & \text { B0 } & \text { Y5 } \\ & 0.28 & 0.39 & 0.43 & 0 \cdot 49 & 0.54 \\ & 1 & 1 & & \\ & & & & \end{array}\right.$

a. $\mathrm{Y} 3$ v. $\mathrm{Y} 5 \quad \mathrm{~T}_{6}=0(\mathbf{P}=0.05)(\mathrm{cc}, 2-4,6-8,9-11,12,13,14,15-16,17-18)$

b. $\mathrm{Y} 3$ v. $\mathrm{B} 0 \quad \mathrm{~T}_{8}=4(\mathrm{P}=0.05)(\mathrm{cc}, 4-5,6-7,8-9,10-11,12,13-14,15-16,17-18)$

c. $\mathrm{Y} 3$ v. $\mathrm{P} 5 \quad \mathrm{~T}_{7}=2(\mathrm{P}=0.05)(\mathrm{cc}, 2-4,6-8,9-11,12,13,14,15-16,17-18)$

d. P3 v. Y5 $\mathrm{T}_{8}=0(\mathrm{P}=0.01)(\mathrm{cc}, 2-4,7-8,9-10,11-12,13-14,15, \ldots 18)$

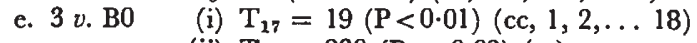

(ii) $\mathrm{T}_{39}=230(\mathrm{P}=0.02)(\mathrm{cs})$

C $\left\{\begin{array}{lccccc}\text { Survival order: } & \text { B0 } & \text { Y5 } & \text { P5 } & \text { Y3 } & \text { P3 } \\ & 0.44 & 0.45 & 0.48 & 0.52 & 0.56 \\ \text { Paired-samples tests: } & & & & & \end{array}\right.$

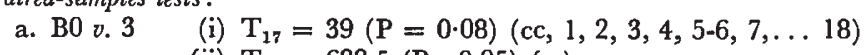

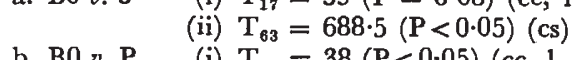

b. $\mathrm{B} 0$ v. $\mathrm{P} \quad$ (i) $\mathrm{T}_{18}=38(\mathrm{P}<0.05)(\mathrm{cc}, 1,2,3, \ldots 18)$

(ii) $\mathrm{T}_{62}=685(\mathrm{P}<0.05)(\mathrm{cs})$

D $\left\{\begin{array}{lccccc}\text { Survival order: } & \text { Y3 } & \text { P5 } & \text { P3 } & \text { B0 } & \text { Y5 } \\ & 0.40 & 0.44 & 0.46 & 0.47 & 0.57 \\ & \vdash & & & & \end{array}\right.$

a. Y3 v. Y5 $\mathrm{T}_{7}=0(\mathrm{P}=0.02)(\mathrm{cc}, 3-5,6-7,8-10,11-13,14-15,16-17,18)$ (date for donors 1 and 2 dropped)

E $\left\{\begin{array}{lccccc}\text { Survival order: } & \text { P3 } & \text { P5 } & \text { Y3 } & \text { B0 } & \text { Y5 } \\ & \mathbf{0 . 4 2} & 0.43 & 0.44 & \mathbf{0 . 4 6} & 0.74 \\ & & & & & \end{array}\right.$

a. P3 v. Y5 $\mathrm{T}_{9}=1(\mathrm{P}<0.01) \quad(\mathrm{cc}, 1-3,6-7,8-9,10,11-12,13-14,15,16,17-18)$

b. P5 v. Y5 $\mathrm{T}_{8}=2(\mathrm{P}=0.02)(\mathrm{cc}, 1-3,6-7,8-10,11-12,13-14,15,16,17-18)$

c. $\mathrm{B} 0 v$. $\mathrm{Y} 5 \mathrm{~T}_{8}=0(\mathrm{P}=0.01)(\mathrm{cc}, 1-2,3-4,6-7,8-9,10,11-12,13-14,16,17-18)$

Notes (i) The horizontal lines below the survival values indicate groups of colour and banding morphs between which differences in survival are not significant.

(ii) The ways in which the data from the different donors have been grouped are indicated in brackets next to the results for each comparison.

$c c=$ data for the four cages combined, $c s=$ data for the four cages considered serially. Other abbreviations as in Table 1.

individual colour and banding morphs, but mid-bandeds survived significantly better than browns, as did pinks.

Site D: (range 17). Y5's survived better than Y3's, but there are no significant differences between either of these and the other morphs, or between the other morphs.

Site E: (range 32). Y5's survived better than each of the other morphs, 
between which there are no differences. (Owing to the high mortality in cage 20 and the restrictions described earlier imposed on the analysis it is not possible to make a formal comparison between Y5 and Y3.)

Further information can be extracted from the data by carrying out three-way (CFM) G tests for each site. These, of course, ignore differences in both morph frequency and survival between donors, so that the FM tests of independence component of such an analysis is uninterpretable. The results of the tests are not given; they confirm the general absence of differences in mortality between the cages at sites A-D, the very pronounced difference at $\mathrm{E}$, and most of the intermorph differences in survival. What is of particular interest, however, is that there is no sign of significant CFM interaction for any of the sites; differences in mortality between the morphs are consistent between the cages at any one site.

\section{(iii) Comparison of survival and selection between the sites}

It is not possible to analyse differences between the sites by a simple four-way (cage $\times$ site $\times$ morph $\times$ mortality) G test, since any one cage at one site does not correspond to a specific cage at another. The most satisfactory analysis allowed by the design is to combine the data for the different donors within each cage, and for the different cages at each site, and to make a three-way (site $\times$ morph $\times$ mortality) comparison between the sites. Table 5 (a) gives the results of such a test. There are very highly significant differences in mortality between the sites; the appropriate STP shows that snails at site A have survived worse than those at any other, between which there are no differences.

In addition the highly significant interaction implies that differences in mortality between the morphs were different in direction between the sites; this is in direct contrast to the non-significant CFM interactions mentioned

TABle 5

Results of comparisons of survival and selection between sites

a. Comparison between sites: three-way $G$ test

\section{Hypothesis tested}

Site $\times$ Morph $\times$ Mortality independence

Site $\times$ Morph independence

Site $\times$ Mortality independence

Morph $\times$ Mortality independence

Site $\times$ Morph $\times$ Mortality interaction

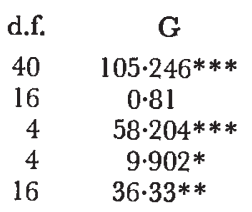

b. Comparison between morphs

Survival order:

Paired-samples tests:

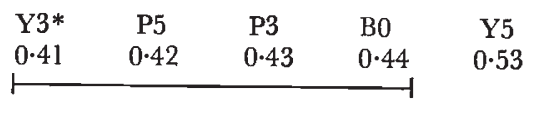
a. $\mathrm{Y} 3$ v. $\mathrm{Y} 5 \quad \mathrm{~T}_{29}=97(\mathrm{P}=0.009)$
b. P5 v. Y5 $\mathrm{T}_{42}=204(\mathrm{P}=0.002)$
c. P3 v. Y5 $\mathrm{T}_{40}=211(\mathrm{P}=0.008)$
d. $\mathrm{B} 0$ v. Y5 $\mathrm{T}_{40}=190(\mathrm{P}=0.003)$

There are no significant differences between $\mathrm{Y} 3, \mathrm{P} 5, \mathrm{P} 3$ and $\mathrm{B} 0$ 
above. That selective differences between the morphs were different between the sites has already been implied by the paired-samples analysis given earlier. At two of the sites there are differences between browns and midbandeds, but these are opposite in direction; at site B there was selection against mid-bandeds and at $\mathrm{C}$ they were favoured.

In spite of the significant interaction in this analysis there is additionally a significant test of FM independence. Yellow five-bandeds have survived the best, and STP's show that these survived significantly better than both Y3's and P5's. Since there were morph frequency differences between the donors, the effect of selection and of interaction could easily be produced if there were differences in mortality between the donors between the sites. It has already been shown that differences in mortality between the donors were similar for all the sites, and paired-samples tests confirm the overall superior performance of Y5's. The results of these tests, which have been carried out by treating the data for all the sites serially, are given in table 5 (b) and not only confirm the $G$ test but show also that Y5's survived significantly better than each of the other morphs.

\section{Discussion}

The analysis reveals a number of differences in survival between the colour and banding morphs, and it is important to consider to what extent the results are likely to be biologically interesting. There are 50 pairedsamples tests which are theoretically possible between five different morphs at five different sites. On two occasions ( $\mathrm{Y} 5 \mathrm{v}$. Y 3 at sites $\mathrm{A}$ and $\mathrm{E}$ ) it is not possible to carry out the tests; in a set of 48 comparisons between two and three should be expected to reach significance at 5 per cent by chance. Five of the comparisons reveal formally significant differences; a further three yield highly significant results. This is a higher number than would be expected by chance alone.

The two yellow morphs are present at relatively lower frequencies than the other three and it might be expected that their performance would consequently show a higher variance. This is in fact the case; of the 10 possible lowest or highest survival rates at the five sites, six involve Y3 or Y5. However, these extreme survival rates involve significant differences on most of those occasions at which they occur (sites B, D and E), and moreover, the overall superiority of Y5's when all the sites are considered together, strongly implies the non-trivial nature of the results. There is thus threefold evidence for selection: At four of the five sites there are significant differences between the morphs; these differences are different between the sites, and overall one morph survived better than each of the others.

It is not known why any of the snails used in the experiment died; mortality was far greater than occurs in adults in natural populations during the summer months. However, the density in the cages was considerably higher than in natural populations and overcrowding is likely to have been a primary cause of stress. Bantock (1974) and Knights (1979) have shown that mortality in population cages is density-dependent.

Although overcrowding may have initiated events culminating in death, death itself is likely to have been caused by physical factors. This is suggested by the variations in mortality which occurred between the sites, and on one occasion between the cages at a site (cage 20, site E). The vegetation 
in this cage grew appreciably less well than in the others at the site, and while there always seemed to be sufficient plant growth to provide a food supply, the snails would consequently have experienced more variable conditions of temperature change, and thereby suffered more stress. Similarly, although there was no obvious vegetational difference between the cages at site $\mathbf{A}$ and those at the others, mortality was very much higher at this site. The valley bottom is known to experience an unusually high diurnal temperature range; this could well exacerbate a lowering of fitness initiated by overcrowding.

Of more interest than the actual mortality is the evidence that it was selective both between morphs within and between sites, and between the donors, and it is interesting to consider what factors may be responsible. Vertebrate predators are clearly not involved, but predators or parasites with access to the cages are not formally excluded. However, a very intricate pattern of biotic relationships would be required to explain wholly the complex selective events which occurred. A more plausible explanation is that physical factors such as temperature are responsible; these are more likely to differ between sites than are the distributions of invertebrate predators. Such factors are already implicated in promoting the observed variations in mortality and it is tempting to implicate them further by assigning them a selective role. If climatic factors only are involved then they have to explain not only why Y5's survived better overall, but also the results peculiar to each site. It is worth pointing out that browns survived better at the site which was probably overall the coolest (site B). In so far as distributional data from the study area suggest that the brown morph is favoured under cool (night) conditions (Bantock and Price, 1975), the result is consistent with a "climatic" interpretation. However, the distributional data suggest also that mid-bandeds are favoured over five-bandeds under conditions of greater temperature variation; they might consequently have been expected to have survived better at site $A$, on the valley floor. This was not the case. Mid-bandeds did, however survive better at site $\mathrm{C}$ : the site most clearly exposed to wind.

It is not clear whether selective events, for which temperature regimes may be responsible, occurred as a consequence of shell appearance as such. The intensity of the pigmentation of shells of $C$. nemoralis has been shown to affect their thermal properties, and those of the snails within (e.g., Heath, 1975; Jones et al., 1977; Garcia, 1978). If such effects were important in the present case, then the survival-order of the different morphs at each site should follow sequences based on pigment intensity. They do not; on three of five occasions the two darkest morphs (B0 and P5) are separated by paler morphs, and on four of five occasions the two palest morphs (Y3 and Y5) are separated by darker morphs.

It is difficult to relate the striking overall success of the yellow fivebanded morph to its local distribution. This morph is particularly rare in this part of Somerset (2 per cent of 12,504 snails from open habitats (Bantock and Price, 1975), and is missing altogether from the Nettlecombe valley. However, it is possible that there are small differences in micro-habitat preference between the morphs; if these preferences are exerted in the cages, stress induced by overcrowding might be least on morphs present at low frequencies. In this case it would not be necessary to propose the action of any climatic factors. Although the two yellow morphs were present at low 
frequencies in the cages, the hypothesis of a relationship between selective intensity and frequency would have to be specifically tested before the argument can be taken further.

Although the primary aim of the experiment was to determine whether selective differences between the morphs could be demonstrated in population cages, the design has additionally allowed the detection of differences in mortality between the donors. Such differences are perhaps to be expected; what is of interest in the present case is that they were position-dependent, in that survival was greatest where changes in morph frequency were steeply clinal.

Numerous authors (e.g., Huxley, 1942) have suggested that steep clines may develop in a continuous population by partially isolated different subgroups acquiring differently coadapted gene complexes as a response to different conditions. "Hybrids" are restricted to a narrow zone since they show a reduced fitness. In the present instance, however, survival was greater in the clinal area. Clarke (1966) has pointed out that modifying genes could affect the slope of a cline and Endler (1977) that positiondependent modifying genes which confer an advantage on the most common genotype in an area can cause an increase in fitness before they reach fixation. The age of the present cline is unknown; it is probably considerable. Morphratio clines of this sort are common in Cepaea. Their origin is obscure, and as in the present case, they can exist in the absence of any obvious environmental discontinuity or variations in density.

The present experimental results involve the demonstration of the repeated success in population cages at different sites, of snails taken from a population where morph frequencies were clinal. Only one geographical area was involved. It would be necessary to show that a similar result could be obtained using individuals from a series of such clines before the generality of the outcome could be accepted.

\section{Conclusions}

The results raise more questions than they answer. Although the field procedure reveals differences in survival between adult individuals of the different morphs, adult mortality is only one component of fitness. It would be of interest to determine whether similar results could be obtained using juveniles, and whether there are differences in behaviour between the morphs which could contribute to selective difference in mortality. (Conversely, of course, there may be important differences in fitness between the morphs unrelated to mortality.) Additionally it is not known to what extent the responses of the snails to conditions in the cages were determined by their circumstances before they were put out; this is of particular relevance to the interpretation of the differences in survival between snails from different places. It is not possible to assign a genetic basis to such differences unless differences in acclimation are formally excluded.

The period of time over which the experiment was conducted may also have been critical. It would be of interest to know whether the direction and intensity of selection at a particular site was constant through the experimental period, and whether similar results could be obtained at other times of year. Although the present results are in some ways puzzling, it seems that population cages provide a technique for the study of natural selection 
in Cepaea, which on the one hand is more "natural" than a totally controlled experimental environment, and on the other is easier to manipulate than are the circumstances of natural populations.

Acknowledgments. - We are grateful to Mr J. H. Crothers, Warden of The Leonard Wills Field Centre, and to members of The Field Studies Council, for their help in the running of the experiment. One of us (C. R. B.) wishes to acknowledge financial help from The Polytechnic of North London.

\section{REFERENCES}

BANTock, C. R. 1974. Experimental evidence for non-visual selection in Cepaea nemoralis. Heredity, 33, 409-412.

BANTOGK, C. R., AND PRICE, D. J. 1975. Marginal populations of Cepaea nemoralis (L) on the Brendon Hills, England. I. Ecology and ecogenetics. Evolution, 29, 267-277.

CAIN, A. J., Sheppard, P. M., AND KING, J. M. B. 1968. Studies in Cepaea. I. The genetics of some morphs and varieties of Cepaea nemoralis (L.). Phil. Trans. R. Soc. (B), 253, 383-396.

GLARKE, B. C. 1966. The evolution of morph ratio clines. Amer. Nat., 100, 389-402.

CLARKE, B. C., ARTHUR, W., HORSLEY, D. T., AND PARKIN, D. T. 1978. Genetic variation and natural selection in pulmonate molluscs. In The Pulmonates, ed. J. Peake. Academic Press, London.

ENdler, J. A. 1977. Geographic Variation, Speciation, and Clines. Princeton Univ. Press.

GARCLA, M. 1978. Écophysiologie de l'escargot Cepaea nemoralis (L.) Helicidae: Quelques conséquences de l'échauffment par l'énergie rayonée. Arch. Zool. exp. gen., 118, 495-514.

HAYWARD, P. J., AND HARVEY, P. H. 1974. The distribution of settled larvae of the bryozoans Alcyonidium hirstum (Fleming) and Alcyonidium polyoum (Hassall) on Fucus serratus (L.). 7. Mar. Biol. Ass., 54, 665-678.

HEATH, D. J. 1975. Colour, sunlight and internal temperatures in the landsnail Cepaea nemoralis (L.). Oeocologia, 19, 29-28.

HuXley, J. s. 1942. Evolution: The Modern Synthesis. George Allen and Unwin Ltd.

JONES, J. S., LEITH, B. H., AND RAWlings, P. 1977. Polymorphism in Cepaea: a problem with too many solutions? Ann. Rev. Ecol. Syst., 8, 109-143.

JONES, J. s., AND PARKIN, D. T. 1977. Experimental manipulations of some snail populations subject to climatic selection. Am. Nat., 111, 1014-1017.

KNIGHTs, R. W. 1979. Experimental evidence for selection on shell size in Cepaea hortensis (Muller). Genetica, 50, 51-60.

LAмотте, м. 1951. Récherches sur la structure génétique des populations naturelles de Cepaea nemoralis (L.). Bull. Biol. Fr. Belg. Suppl., 35, 1-239.

RAtsey, s. 1973. The climate at and around Nettlecombe Court, Somerset. Field Studies, 3, $741-757$.

SOKAL, R. R., AND ROHLF, F. J. 1969. Biometry. Freeman, San Francisco.

WolDA, H. 1969. Fine distribution of morph frequencies in the snail Cepaea nemoralis near Groningen. 7. An. Ecol., 38, 305-327. 